BEduManageRs Journal

Borneo Educational Management and Research Journal, Vol.1, No.1, 2020

ISSN: 2747-0504

\title{
Manajemen Mutu Dosen
}

\author{
Susanto AS ${ }^{1}$, Husainie Usman ${ }^{2}$, Hasbi Sjamsir ${ }^{3}$ \\ Universitas Mulawarman \\ e-mail: sjamsirhasbi@yahoo.com
}

\begin{abstract}
The purpose of this research were to know:quality management of lecturer in Caturdharma of Higher Education and find new concept of lecturer qualitymanagement.The study used a qualitative approach with case study type. Data were collected through participantobservation,in-depth interviews, and documentation.The research instrument is the researcher himself.The key person were the Chairman,Vice Chairman, and Stikes lecturer. Data were analyzed using Miles,Huberman, \&Saldana model. Validity of data through credibility, transferability, dependability, and confirmability. As the result of this research about the quality management lectures were:(1)learning area is fulfilled if according to planning, implementation and supervision standard;(2)the field of study is determined by eight standards;(3) the field of Community Service is determined by eight standards;(4)the field of Al-Islam and Kemuhammadiyahan is determined by the introduction, appreciation, and practice of the Qur'an,Hadith, and Ra'yu;Amar ma'ruf nahi munkar, and live Muhammadiyah, do not seek livelihood in Muhammadiyah.(5)A new concept of lecturer quality management is nine steps.
\end{abstract}

Keywords:management, quality, lecture, Caturdharma, Al-Islamand and Ke-Muhammadiyahan

\section{PENDAHULUAN}

Studi pendahuluan di Stikes Muhammadiyah Samarinda kenyataan (das sein) menunjukkan bahwa:(1)dosen lebih disibukkan dengan urusan mengajar daripada melakukan penelitian dan Pengabdian pada Masyarakat (PpM);(2) penelitian dosen dan penelitian dosen melibatkan mahasiswa terkendala waktu dan dana;(3) PpM terkendala waktu dan tempat untuk melaksanakannya;(4)belum ada persamaaan persepsi dalam menerapkan Al-Islam dan Kemuhammadiyahan, dan(5) belum ada konsep manajemen mutu dosen untuk melaksanakan Caturdharma PT di Stikes Muhammadiyah Samarinda.

Stikes Muhammadiyah Samarinda diharapkan (das sollen):(1)memiliki waktu yang proporsional untuk melaksanakan Caturdharma;(2)penelitian dosen dan penelitian dosen melibatkan mahasiswa terkendala didukung waktu dan dana;(3) PpM didukung waktu dan dana;(4) terjadi persamaaan persepsi dalam menerapkan Al-Islam dan Kemuhammadiyahan, dan (5) menemukan konsep model manajemen mutu dosen untuk melaksanakan Caturdharma PT di Stikes Muhammadiyah Samarinda.

Manajemen mutu dosen di Stikes Muhammadiyah Samarinda dipilih sebagai tempat penelitian karena:(1) sejak berdiri pada tahun 2009 telah melahirkan sejumlah kader bangsa di bidang kesehatan;(2) mutu pendidikan tinggi kesehatan swasta belum merata;(3) sudah mendapat tempat di hati masyarakat tetapi belum mampu menempatkan diri sebagai pendidikan tinggi kesehatan terbaik pesaingnya baik PTN maupun PTS;dan (4) ipteks dan informasi membutuhkan kepemimpinan yang visioner, budaya organisasi yang berorientasi pada mutu untuk mencapai visi dan misi belum efektif;(5) masih berakreditasi B.

Penelitian ini bertitik tolak dari penelitian Wardani (2015),yang menemukan manajemen ketenagaan dilaksanakan dengan strategi pemberdayaan SDM tenaga pendidik dan Tenaga Kependidikan (PTK) yang profesional dengan komitmen tinggi sesuai standar PTK. Penelitian ini melanjutkan dengan meneliti mutu dosen PTS di Stikes Muhammadiyah Samarinda.

Penelitian juga bertitik tolak dari penelitian Mimin Emi Suhaemi \& Nur Aedi (2015) yang menemukan, “... the management strategy of lecturers' competence improvement has not been well-coordinated; the management aspect as well as lecturer continuous professional development has failed to consider reward and punishment, hence affecting lecturer competences." 
BEduManageRs Journal

Borneo Educational Management and Research Journal, Vol.1, No.1, 2020

ISSN: 2747-0504

Penelitian ini melanjutkan penelitian Mimin Emi Suhaemi \&Nur Aedi (2015) dengan menggunakan konsep manajemen mutu dosen di bidang Caturdharma PT.

Penelitian ini juga bertitik tolak dari penelitian Akenyemi \& Abiddin (2013) yang menyimpulkan,"Quality higher education system will produce quality skills and quality human capacity.....................TQM and CQI implementation in the university system will go a long way in expanding the skill capacity of academic staffs and consequently that of students. " Penelitian ini melanjutkannya dengan meneliti mutu dosen Stikes Muhammadiyah Samarinda menggunakan pendekatan kualitatif, jenis studi kasus, dan QA.

Manajemen mutu dosen di Stikes Muhammadiyah Samarinda perlu diteliti karena jika tidak diteliti dikhawatirkan mutu dosen menurun, mutu pelaksanaan Caturdharma PT menurun, mutu lulusan menurun, animo mahasiwa menurun, akreditasi menurun, keluhan masyarakat meningkat dan akhirnya Stikes Muhammadiyah Samarinda ditutup.

Rumusan masalah penelitian adalah, "Bagaimana manajemen mutu dosen bidang Caturdharma PT dan konsep baru manajemen mutu di Stikes Muhammadiyah Samarinda?"

Tujuan penelitian adalah untuk mendeskripsikan manajemen mutu dosen di bidang:(1) pendidikan dan pengajaran;(2) penelitian;(3) PpM;(4)Al-Islam dan KeMuhammadiyahan;dan (5)menemukan konsep baru manajemen mutu dosen dalam melaksanakan Caturdharma perguruan tinggi.

\section{KAJIAN TEORI}

Manajemen berasal dari bahasa Latin managere yang artinya menangani atau mengelola. Manajemen dapat ditinjau dari tugas dan fungsi.

Manajemen sebagai tugas menurut Follet (1924), "Management is the art of getting results through people." Sejalan dengan pendapat Follet, Zajda \& Gamage (2009) menyatakan, "Educational administration is the process of working with, and through others."

Manajemen dalam penelitian ini ditinjau dari fungsi. Minimal ada 24 pendapat ahli tentang fungsi manajemen (Husaini Usman,
2016). Satu di antaranya adalah menurut (Terry 1974) yaitu Planing, Organizing, Actualualizing, and Controling (POAC). Pendapat Terry tersebut dipilih karena sederhana, praktis, komprehensif, dan berlaku di sistem pemerintahan Indonesia. Fungsi POAC dibatasi pada PAC karena $\mathrm{O}$ berupa struktur organisasi sudah dibakukan oleh pemerintah.

Manajemen diperlukan karena keterbatasan 7M (men, money, material, machines, methods, marketing, minutes) dan untuk meningkatkan mutu. Mutu $85 \%$ ditentukan oleh manajernya, sisanya $15 \%$ ditentukan bawahannya (Deming, 1986) atau menurut pendapat Juran (1989), 80\% mutu ditentukan oleh manejemennya, sisanya $20 \%$ oleh faktor lainnya.

Mutu adalah: sesuai kebutuhan (Deming), cocok dengan produk (Juran), sesuai syarat (Crosby), sesuai standar (Burnham), nafsu dan kebanggaan (Peter \& Austin), kepuasan pelanggan (IBM), dan memuaskan pelanggan sepuas-puasnya (Ford Motor) (Sallis, 2008). Definisi mutu yang dipilih menurut Burnham (1997) karena definisi ini yang berlaku di Indonesia dan didukung oleh hasil penelitian Dwi Esti Andriani (2012) yang menemukan bahwa mutu dosen adalah dosen yang memenuhi atau melampaui standar. Dosen adalah tenaga profesional dengan tugas utama melaksanakan Tridharma PT atau Caturdharma PT di Stikes Muhammadiyah Samarinda.

Tugas utama dosen adalah memberikan layanan bermutu tinggi kepada mahasiswanya sebagai pelanggan primernya (Sallis, 2008);Maria \& Marian;2014:46; \& Anonim a, 2016) dan memberikan pelayanan prima kepada setiap pelanggan secara terus-menerus dengan menerapkan delapan indikator mutu layanan prima (Anonim b, 2016).

Hirarki mutu menurut Sallis (2008) adalah mulai terendah yaitu inspeksi, Quality Control (QC), Quality Assurance (QA), sampai tertinggi yaitu Total Quality Management (TQM). Quality Assurance dipilih karena hirarki ini yang berlaku di Indonesia.

Penelitian Siti Rokhmi Lestari (2014) menyimpulkan bahwa perencanaan dan pengembangan dosen ternyata tidak diimplementasikan sepenuhnya sesuai dengan peraturan yang yang berlaku. Persamaan penelitian Siti Rokhmi Lestari dengan penelitian ini adalah sama-sama: meneliti mutu dosen di sekolah tinggi swasta (Sekolah Tinggi 
BEduManageRs Journal

Borneo Educational Management and Research Journal, Vol.1, No.1, 2020

ISSN: 2747-0504

Pariwisata) menggunakan model penjaminan mutu. Perbedaannya adalah penelitian Siti Rokhmi Lestari menggunakan evaluasi, sedangkan penelitian ini menggunakan pendekatan kualitatif dengan jenis studi kasus. Tempatnya di Sekolah Tinggi Pariwisata Yogyakarta, sedangan penelitian ini di Stikes Muhammadiyah Yogyakarta.

Penelitian Yohanes Suharso (2014) menemukan bahwa kinerja dosen tercermin dari produktivitas dalam mengamalkan Tridharma Perguruan Tinggi. Persamaan penelitian Yohanes Suharso dengan penelitian ini adalah sama-sama: meneliti dosen, tempatnya di perguruan tinggi swasta. Perbedaan penelitian Yohanes Suharso dengan penelitian ini adalah jika penelitian Yohanes Suharso meneliti produktivitas dosen di bidang Tridharma PT, maka penelitian ini meneliti di bidang Caturdharma PT, tempatnya di IKIP Veteran Semarang, sedangkan tempat penelitian ini di Stikes Muhammadiyah Samarinda.

Sri Abidah Suryaningsih (2012) dalam penelitiannya menemukan bahwa hasil dari pengembangan ilmu pengetahuan dan keterampilan yang dimiliki dosen di Fakultas Tarbiyah dapat dilihat pada peningkatan kinerja dosen dalam proses pembelajaran; dosen yang bersifat statis menjadi lebih dinamis; pola pembelajaran tradisional menjadi moderen yang tepat guna. Peningkatan ini diikuti oleh dosen muda dan dosen tua. Perbedaan penelitian Sri Abidah Suryaningsih dengan penelitian ini adalah jika penelitian Sri Abidah Suryaningsih meneliti di IAIN Sunan Ampel Surabaya (PTN), maka peneliti melaksanakan penelitian di Stikes Muhammadiyah Samarinda (PTS). Jika penelitian Sri Abidah Suryaningsih meneliti pengetahuan,sikap, keterampilan dalam pembelajaran oleh dosen, maka penelitian meneliti mutu pelaksanaan Caturdharma PT oleh dosen Stikes Muhammadiyah Samarinda.

Penelitian Gudo, Olet, \& Oanda (2011) menyimpulkan, "It was found that public universities did not have the necessary physical facilities to effectively offer service to its current student body." jika penelitian Gudo, Olet,\&Oanda menggunakan pendekatan kuantitatif, maka penelitian ini menggunakan pendekatan kualitatif. Jika penelitian Gudo, Olet,\&Oanda meneliti fasilitas fisik PTS, maka penelitian ini meneliti mutu dosen di bidang Caturdharma Perguruan Tinggi. Persamaan penelitian ini dengan penelitian Gudo, Olet, \& Oanda adalah sama-sama meneliti PTS.

Endah Christianingsih

(2011)

menyimpulkan bahwa ada pengaruh pengaruh kepemimpinan visioner dan kinerja dosen terhadap mutu Unisba Bandung. Perbedaan penelitian ini dengan penelitian Endah Christianingsih adalah jika penelitian Endah Christianingsih meneliti kepemimpinan visioner sebagai leader dan kinerja dosen serta pengaruhnya terhadap mutu Unisba Bandung dengan pendekatan kuantitatif, maka penelitian ini meneliti mutu dosen sebagai follower di Stikes Muhammadiyah dengan pendekatan kualitatif jenis studi kasus. Persamaannya adalah sama-sama meneliti mutu dosen di PTS.

Mardi Wiyono (2009) dalam penelitiannya menyimpulkan bahwa peran dosen dalam organisasi profesi masih rendah sehingga dapat dikatakan bahwa kesungguhan dosen dalam menjalankan profesinya masih kurang. Perbedaan penelitian Mardi Wiyono dengan penelitian ini adalah jika Penelitian Mardi Wiyono dilaksanakan di Universitas Negeri Malang (PTN) maka penelitian ini dilaksanakan di Stikes Muhammadiyah Samarinda (PTS), Jika penelitian Mardi Wiyono meneliti tugas dosen dalam melaksanakan tridahrma PT, maka meneliti mutu dosen dalam melaksanakan Caturdharma PT. Persamaannya adalah samasama meneliti mutu dosen dengan pendekatan kualitatif.

Penelitian Hambali (2001:157) menyimpulkan bahwa faktor yang mempengaruhi pengembangan kualitas dosen adalah faktor internal dan eksternal. Perbedaan penelitian Hambali dengan penelitian ini adalah jika penelitian Hambali meneliti pengembangan mutu dosen STAIN Malang (PTN), maka penelitian ini meneliti mutu dosen Stikes Muhammadiyah Samarinda (PTS). Jika penelitian Hambali meneliti tentang faktor internal dan eksternal yang mempengaruhi mutu dosen, maka penelitian ini meneliti mutu dosen dipengaruhi oleh mutu pelaksanaan Catudharma PT.

Emmy Fakri Gaffar (1992) dalam penelitiannya menyimpulkan bahwa mutu dosen diukur dengan kemampuannya dalam melaksanakan Tridharma PT. Perbedaannya dengan penelitian ini adalah jika Emmy Fakri Gaffar meneliti mutu dosen melaksanakan Tridharma PT di IKIP Bandung (PTN), maka 
BEduManageRs Journal

Borneo Educational Management and Research Journal, Vol.1, No.1, 2020

ISSN: 2747-0504

penelitian ini meneliti mutu dosen melaksanakan Caturdharma PT di Stikes Muhammadiyah Samarinda (PTS). Persamaan penelitian Emmy Fakri Gaffar dengan penelitian ini antara lain: sama-sama meneliti mutu dosen dengan pendekatan kualitatif.

\section{METODE PENELITIAN}

Metode penelitian menggunakan pendekatan kualitatif dengan jenis studi kasus. Instrumen penelitian adalah peneliti sendiri (human instrument). Key informant adalah Ketua Stikes Muhammadiyah Samarinda.

Teknik pengambilan sampel dalam penelitian kualitatif bersifat purposive dalam hal ini responden penelitian adalah Ketua, Wakil, dan Dosen Stikes Muhammadiyah Samarinda. Teknik pengumpulan data yang digunakan adalah wawancara mendalam, observasi partisipasi, dan dokumentasi. Wawancara mendalam dengan Ketua Stikes menggunakan Panduan wawancara dan dilakukan sebanyak tiga kali untuk mendapatkan data berupa jawaban yang sudah jenuh (redundancy) dan memeriksa jawaban pertama wawancara sudah benar pada jawawaban wawancara terakhir (ketiga). Selanjutnya, hasil analisis data dan simpulan diparaf oleh Ketua Stikes Muhammaddiyah Samarinda. Untuk memeriksa kebenaran jawaban Ketua Stikes dilakukan wawancara mendalam dengan Wakil dan seorang perwakilan dosennya dengan cara seperti melakukan wawancara dengan Ketua Stikes di atas. Kegiatan ini disebut triangulasi responden.

Hasil final wawancara denga Ketua Stikes selanjutnya diperiksa kebenarannya berdasarkan observasi partisipasi dan dokumentasi yang tersedia dengan menggunakan Panduan observasi. Kegiatan ini disebut triangulasi teknik pengumpulan data. Analisis data yang digunakan dalam penelitian ini adalah model Miles, Huberman, \& Sadana (2014) dengan langkah-langkah: pengumpulan data, penyajian (display), kondensasi (rangkuman) data, dan simpulan/verifikasi. Keabsahan data dilakukan melalui: kredibilitas, transferabilitas, dependabilitas, dan komfirmabilitas.

\section{HASIL DAN PEMBAHASAN}

Penelitian menemukan bahwa manajemen mutu dosen di bidang Pendidikan dan Pengajaran di Stikes Muhammadiyah
Samarinda meliputi perencanaan, pelaksanaan, dan pengawasan pembelajaran. Temuan ini mendukung fungsi manajemen yang dikemukan oleh semua pendapat ahli manajemen seperti Taylor, 1911, Fayol, 1916; Gullick \& Urwick, 1937; Mayo, 1948; Terry, 1960, dan Lanier, et al. (1986), Gutek (1988). Temuan penelitian ternyata bertentangan dengan penelitian Edy (2017), Mimin Emi Suhaemi \& Nur Aedi (2015), dan Siti Rokhmi Lestari (2014). Tetapi mendukung penelitian Wardani (2015), Yohanes Suharso (2014), Akinyemi \& Abiddin (2013), Dwi Esti Andriani (2012), Sri Abidah Suryaningsih (2012), Endah Christianingsih (2011), Hambali (2001). Perencanaan pembelajaran mendukung teori Banghart \& Trull, (1973) dan Zajda \& Gamage (2009: 106). Pelaksaaan pembelajaran perlu fasilitas memadai mendukung penelitian Gudo, Olet, \& Oanda (2011), dan mendukung pendapat Centra (1982). Pengawasan pembelajaran mendukung penelitian Emmy Fakri Gaffar (1992).

Manajemen mutu dosen di bidang penelitian ditentukan oleh: (1) mutu peneliti, (2) subtansi, (3) proses, (4) hasil, (5) penilaian, (6) sarpras, (7) pengelolaan, dan (8) pendanaan penelitian. Temuan penelitian mendukung penelitian Emmy Fakri Gaffar (1992), Ryan \& Cooper, (1984), Ruddock, \& Horkins (1989), dan Gudo, Olet, \& Oanda (2011).

Manajemen mutu dosen di bidang PpM ditentukan oleh: (1) mutu pengabdi pada masyarakat, (2) subtansi, (3) proses, (4) hasil, (5) penilaian, (6) sarpras, (7) pengelolaan, dan (8) pendanaan PpM.Temuan penelitian mendukung penelitian Emmy Fakri Gaffar (1992), Ryan \& Cooper, (1984), Ruddock, \& Horkins (1989), dan Gudo, Olet, \& Oanda (2011). PpM menganut asas ilmu amaliah dan amal-ilmiah, kerja sama, kesinambungan, edukatif, dan pengembangan.

Manajemen mutu dosen di Bidang Al-Islam dan Ke-Muhammadiyahan bersumber pada dari tiga sumber yaitu Al-Qur'an (kitabullah), As-Sunnah (kini dihimpun dalam Hadits),dan ra'yu atau akal pikiran manusia yang memenuhi syarat untuk berijtihad. Dosen bekerja sebagai ibadah dengan hati yang ikhlas, para dosen wajib menerapkan semboyan menghidupi pendidikan tanpa mencari penghidupan dari keuntungan, berbuat amar ma'ruf nahi munkar. 
BEduManageRs Journal

Borneo Educational Management and Research Journal, Vol.1, No.1, 2020

ISSN: 2747-0504

Konsep baru manajemen mutu dosen di bidang Caturdharma perguruan tinggi adalah; (1) memahami peraturan Catur Dharma Perguruan Tinggi, (2) membuat SOP Catur Dharma Perguruan Tinggi, (3) Mensosialisasikan SOP, (4) mengujicobakan SOP, (5) merevisi SOP, (6) melaksanakan SOP, (7) memonitor SOP, (8) mengevaluasi SOP, dan (9) membuat SOP baru hasil evaluasi.Temuan caturdharma tersebut berbeda dengan penelitian Emmy Fakri Gaffar (1992) tetapi mendukung penelitian Hambali (2001).

\section{KESIMPULAN}

Simpulan penelitian adalah manajeman mutu dosen:(1) bidang pembelajaran terpenuhi jika sesuai standar perencanaan, pelaksanaan, dan pengawasan;(2)bidang penelitian ditentukan oleh delapan standar;(3)bidang Pengabdian kepada Masyarakat ditentukan oleh delapan standar;(4)bidang Al-Islam dan Kemuhammadiyahan ditentukan oleh pengamalan Al-Qur'an, Hadist, dan Ra'yu; (5)Konsep baru manajemen mutu dosen ada sembilan langkah.

Rekomendasi penelitian adalah hasil penelitian ini diharapkan berguna untuk:(1)Untuk dosen dalam meningkatkan mutu pendidikan dan pengajaran, penelitian, pengabdian pada masyarakat, serta Al-Islam dan Ke-Muhammadiyahan;(2)Bagi Ketua Stikes Muhammadiyah Samarinda untuk meningkatkan mutu dosennya;(3)Bagi Koordinator Perguruan Tinggi Swasta untuk meningkatkan mutu dosen; dan bagi (4)Bagi Lembaga Penjaminan Mutu Stikes Muhammadiyah Samarinda untuk masukan dalam merevisi Standar Operasional Prosedur (SOP).

\section{DAFTAR PUSTAKA}

Akenyemi, G.M., \& Abiddin, N.Z. Quality Administration and Management in Higher Education in Negeria: Implications for Human Resources Development. (nternational Education Studies. Voume 6, Nomor, 4, 2013), p. 225.

Anonim,a.Konsep pelayanan prima. (Jakarta: Lembaga Administrasi Negara. 2016).
Anonim,b.Pelayanan prima:Perilaku pelayanan prima. (Jakarta:Lembaga Administrasi Negara. 2016)

Banghart, F.W., \& Trull, A.T. Educational planning. (New York: The Macmillan Company, 1973).

Burnham, J.W. Managing quality in schools. Second Edition. (London: Prentice Hall, 1997).

Deming, W.E. Out of the cricis. (Mssachusetts: MIT Center Avanced, 1986).

Dwi Esti Andriani, Program Peningkatan Mutu Guru Berbasis Kebutuhan, (ISSN 08521921 Vol 23 Nomor 5, 2012).

Endah Chrisatiningsih, Manajemen Perguruan Tinggi, (Jurnal Pendidikan, Volume 9 Nomor 18, 2011)

Emmy Fakry Gaffar, Perencanaan Pendidikan Teori dan Metodologi. (Bandung: FPS IKIP Bandung, 1992).

Follet, M.P. Creative experience. (New York: Longman, 1924).

Gudo,C.O.,Olel,M.A.,\&Oanda, I.O. University Expanpnsion in Kenya and Issues of Quality Education: Callenges and Opportunities. (International Journal of Business and Socil Science. Volume 2 Nomor 20, 2011), p. 203.

Hambali. Manajemen Pengembangan Kualtas Dosen. (Jurnal Pendidikan Jilid 12 Nomor 4., 2001).

Husaini Usman. Manajemen, Teori, dan Pendidikan, (Jakarta: Pt. Bumi Aksara, 2016)

Juran, J,M., Juran of leadership for quality. (New York: Macmillan, 1995).

Larsen,K.,et al.,Learning Organization, http//homenycap.tt.com/klarsen/learning/l earnog.,1996.

Mardi Wiyono, Profesional Dosen dalam Program Penjaminan Mutu, (Jurnal Ilmu Pendidikan. Jilid 16 Nomor 1, 2009).

Maria, M., \& Marian, R. Quality Management in Higher Education Institutions. Hoilistic Marketing Management, 2014, p. 46.

Mimin Emi Suhaemi \& Nur Aedi. A Manageebt Strategy for the Improvement of Private Universities Lecturers' Professional Competences. International Education Studies., Volume 8, Nomor 12, 2015, p. 241. 
BEduManageRs Journal

Borneo Educational Management and Research Journal, Vol.1, No.1, 2020

ISSN: 2747-0504

Miles, M.B., Huberman, A.M.,\& Saldana, J., Qualitative data analysis:A methods sourcebook. Edition 3. (London:Sage, 2014).

Sallis, E., Total Quality Management In Education. (London:Cogan Page Limited, 2008).

Siti Rukhmi Lestari. Manajemen Pengembangan Dosen sebagai Upaya Pendekatan Mutu Sekolah Tinggi Pariwisata AMPTA Yogyakarta. (Jurnal Media Wisata, Volume 12 Nomor 2. November 2014), p. 87.

Sri Abidah Suryaningsih., Pengembangan Profesi Dosen. (Jurnal Tehnologi Pendidikan. ISSN 1979-6692, Volume 5 Nomor 1., 2012).

Taylor, E. B., The Science of culture. http://www2.truman.edu/ rgraber/cultev/ tylor.html. (Diakses pada tanggal 20 Fbruari 2012)

Terry, G.R., The principles of management. Third Edition. (Homework, Illinois: Richard Irwin., 1960).

.Wardani., Manajemen Mutu Pendidikan di SMKN 2 Surakarta. (Jurnal Pendidikan. Volume 4 Nomor 1., 2015).

Yohanes Suharso., Pengambilan Keputusan Pembinaan Karier Dosen PTS. (Jurnal Manajemen Pendidikan. Volume 9 Nomor 1. 2014).

Zajda,J.,\& Gamage, $\quad$ D.T. $\quad$ (Eds)., Decentralisation, school-based manajement, and quality. (Melbourne:Springer., 2009). 